\title{
Digital Identity: A Gendered Analysis of Self-Presentation by Chinese National Swimming Team Athletes on Weibo
}

\author{
Chenyu $\mathrm{Ni}^{1, *} \mathrm{Ge} \mathrm{Liu}^{2}$
}

\author{
${ }^{1}$ Department of Digital Humanities, King's College London, London, UK \\ ${ }^{2}$ Department of Physical Education and Research, Northwest University, Xi'an, Shaanxi, China \\ *Corresponding author. Email: chenyu_ni@163.com
}

\begin{abstract}
Guided by Goffman's concepts of impression management and gender display, this research applied the content analysis to study the Weibo photo posts of six athletes from the Chinese national swimming team and explore the online impression management styles and gender differences among them. The results revealed that there were significant gender differences in the online impression management of Chinese national swimming team athletes, which were mainly reflected in the aspects of selfies and clothing. Further, this research also verified the applicability of Goffman's gender display concept in the digital age. Although this concept was developed in the context of advertising research, many rules still applied to the online photo-based self-presentation of swimmers, the most apparent of which were the relative size and the feminine touch.
\end{abstract}

Keywords: identity, self-presentation, athletes, media, gender

\section{INTRODUCTION}

With the integration of social media into people's lives, more and more people begin to show themselves in the online world. Similarly, Marshall (2010) points out that the popularity of new media means that various public figures have to choose to highlight their identities in online network environments by selfpresentation. Sports stars are no exception, as there are more and more sportspeople start to use social media (Smith and Sanderson, 2015). Nowadays, many sports teams and athletes have their own public social media accounts, which are regarded by them as a tool to directly talk about their lives without being filtered by marketing teams or public relations teams (Pegoraro, 2010). According to Smith and Sanderson (2015), athletes use social media can make their fans closer to them because it gives athletes more opportunities to share their diverse identities than media coverage.

Today, many scholars have studied the selfpresentation behaviors of various athletes on social media. For example, Geurin-Eagleman and Burch (2016) have explored the behaviors of Olympic athletes' Instagram posts from the perspective of personal brand building and gender difference. Kassing and Sanderson (2010) have also analyzed how fans experience major sporting events via Twitter and their social relationships with athletes on this platform. Additionally, Emmons and Mocarski (2014) applied brand theory to conduct a content analysis of the visual components of male and female professional athletes' photos on Facebook. Although many scholars' studies have shown that it is a liberation for athletes to show themselves directly through social media, Smith and Sanderson (2015) claim that improper use of personal social media accounts can also bring about many adverse effects on athletes' reputation and even career. In short, no matter from which perspective scholars study athletes' social media use behaviors, their focus so far has been on social media platforms such as Twitter, Facebook and Instagram. However, many Chinese sports stars have their public accounts on Weibo, one of the most popular social media among Chinese netizens, and their behaviors on the platform have received little attention or discussion from the academia.

In this vein, this research was a preliminary exploratory study and attempted to update the content analysis of photos posted by athletes on social media by analyzing the gender differences of Chinese national swimming team athletes' Weibo photos. It complemented the existing literature gaps in the selfpresentation of athletes on social media regarding Weibo and specific countries (China). Also, it verified the applicability of Goffman's gender display theory in the digital age. 


\section{LITERATURE REVIEW}

\section{A. Goffman's impression management and gender display}

In daily life, some people can realize that they are playing particular roles, while others cannot (Adrian, 2008). Successfully playing a role is Goffman's definition of his impression management theory (Goffman, 1959). Specifically, Goffman defines people's behavior in interpersonal communication as "performing". In his opinion, people always consciously or unconsciously play different roles in daily life according to the changes of the environment in order to leave an ideal impression on others. Besides, Goffman also classifies the places of self-presenting as front stage and backstage. On the front stage, individuals need to make efforts to perform to the audience, which follows and embodies specific standards (Barton, 2004), or refers to specific scripts. However, on the backstage, individuals tend to be less scripted and less self-presented (Smith and Sanderson, 2015), as they need to prepare for their performances and get relaxed.

Goffman also extends this impression management theory to gender studies. In the book Gender Advertising (Goffman, 1976), he focused on the facial expressions, head and neck posture, arm placement, fingertip movements and eyes of participants (Wang, 2018), and proposed the concept of gender display. Precisely, gender display can be regarded as a sign to distinguish the way men and women participate in social occasions, in which both performers and viewers tend to believe that their behaviors are natural (Wallis, 2011). However, Goffman (1976) supposes that these habitual body postures and etiquette of men and women are the best decoders to understand the behaviors and gender relations in public places and the social mechanism operating behind them (Wang, 2018). For him, people's gender behaviors, as well as concepts of masculinity and femininity, are scripts that people consciously or unconsciously follow due to the existence of particular environments (Wallis, 2011).

Beside, Goffman also identifies five gender displays through his research. The first one is the relative size. He explains that men are always taller than women in advertising pictures, which is a sign of males' prominent social status (ibid). The second is the feminine touch. He claims that women touch themselves more than men to show a sense of physical preciousness. The third one: function rating, which emphasizes that women do not often play professional or active roles in advertising as much as men do. The fourth type is the ritualization of subordination. Goffman claims that in advertisements, women more or less show the ritualization of obedience, such as "bending the knee", "lowering the head", "bending the body." The fifth is the licensed withdrawal, in which women are portrayed as detached from reality and dependent on others. For example, they always look away, show fear or anxiety, or cover their face with their fingers (Paul and Sheets, 2012). In short, these five definitions all demonstrate a subordinate and submissiveness manner of women (Smith and Sanderson, 2015).

\section{B. Athletes' online self-presentation and gender differences}

Goffman's impression management theory, however, focuses primarily on face-to-face interactions with people in offline life. Today, digital media has created a new impression management space in which the audiences are not required to be present in time. Therefore, they also provide more forms for people's impression management (Smith and Sanderson, 2015).

Many scholars have discussed Goffman's impression management theory in the context of the digital age. For example, Hogan (2010) believes that Goffman's impression management focuses on scenarios. However, on online social networking platforms, people are more like "curators" who use "exhibitions" rather than "performance" for impression management. In other words, because photo collections and blog content can be viewed, managed, and reposted, this makes online self-presentation different from that in offline, which needs to be done in person and cannot have prior intervention. In addition, Zhao et al. (2013) made a more specific study on people's longterm data collection behaviors on Facebook based on theories of Goffman and Hogan. He claims that people's experience of Facebook is made up of three distinct functional areas, that is "a performance region for managing recent data and impression management, an exhibition region for longer term presentation of selfimage, and a personal region for archiving meaningful facets of life "(Zhao et al., 2013, p.1).

As the field of online impression management attracts more and more attention in academia, many scholars have also conducted researches on athletes' self-presentation behaviors on social media (Lebel and Danylchuk, 2014; Wallace et al., 2011; Pegoraro, 2010). Besides, scholars taking Smith and Sanderson (2015), Shreffler, Hancock and Schmidt (2016) as examples pay more attention to gender differences in athletes' impression management on social media. Guided by Goffman's impression management and gender display theories, as well as the methods of content analysis and text analysis, Smith and Sanderson (2015) explored the self-presentation styles and gender differences of professional athletes on Instagram. They found that male and female athletes showed differences in ritualistic touching, sizes in the photographs, and suggestive manners. Besides, they also suggest that the 
"away from the game" behaviors of athletes on Instagram could lead to not only positive social effects due to authenticity but also adverse effects due to publicity. Furthermore, Shreffler, Hancock and Schmidt (2016), unlike scholars who study the content of posts, focus on how female athletes use Twitter profile pictures to construct their identities. Through content analysis, they found that unlike traditional media portraying "sexy", "mother", "girlfriend", the athletic ability was the most shared theme and identity factor among female athletes.

Given the existing academic research on the impression management of athletes on social media and the blank of the research on the impression management of Chinese athletes on Weibo, this research analyzed the gender differences in Weibo photos of Chinese national swimming team athletes under the guidance of the concepts of Goffman's gender display and impression management. Besides, this research also contributed to verifying the applicability of Goffman's gender display theory in the digital age. To guide this research, the research questions of are as follows:

Q1: What were the gender differences in the photobased posts on Weibo of the Chinese national swimming team's athletes?

Q2: Does Goffman's theory of gender display apply to the self-presentation of the Chinese national swimming team's athletes on social media?

\section{METHOD}

Since the research objects of this research were the Chinese national swimming team athletes and their photos related to themselves published on Weibo, the content analysis method was selected as the guiding method. According to White and Marsh (2006), content analysis is a systematic and rigorous method, which is often used by scholars to study communication and to process many types of documents such as text, pictures, audio, or video (Alan and Bryman, 2011). It is also an effective method for the interpretation of nonverbal behaviors (Wallis, 2011). Thus, in this research, content analysis was an ideal choice for encoding images.

\section{A. Data collection}

Since the subjects of this research were Chinese national swimming team athletes, the selected Weibo photos were all from the current Chinese national swimming team athletes. In order to better highlight their characteristics in self-presentation and gender differences, the researchers selected 3 (6 in total) players from the men's and women's teams respectively for analysis based on their number of Weibo followers and number of posts.

\section{B. Data coding}

Starting on March 20, 2020, the researchers began collecting 30 photo-based posts from each athlete backward. In order to analyze the data accurately, emojis, landscapes, sundries, food, and other pictures unrelated to the athletes themselves were not collected. After data collection, the researchers encoded the image-based content on the adaptation of the coding schemes of Goffman (1976), Geurin-eagleman and Burch (2016) as well as Smith and Sanderson (2015). Precisely, all data were placed in the following 11 items: athlete's name, gender, sizes of athletes in photos (single photo, bigger than others, as big as others, smaller than others), clothing (unrevealing, revealing/swimsuit), breasts/buttocks (not the point, the point, the emphasis), touch (no touching, touch), posture (normal, cause knee/body arched), emotions (positive, dissociative, depressed), photo types (selfie, headshot, half body, full body) photo contents (about personal life, business and sports life, other sports or athletes), the focus of photos (whether the athlete is the focus of the photo).

\section{RESUlts}

Because one athlete had permission on her Weibo, which allowed her posts to be seen by other users for only half a year, the researchers ended up collecting 177 valid photos, 87 from women and 90 from men.

Q1 asked what the gender differences in photos posted by Chinese national swimming team athletes on Weibo were. The researchers found significant differences and notable differences in some items. These differences were mainly reflected in the sizes of athletes in photos, clothing, breasts/buttocks, the touch of self, photo types, the focus of photos.

In terms of sizes of athletes in photos, the proportion of single photos for male and female athletes was roughly equal at $66 \%$ and $70 \%$, respectively. However, in group or group photos of two athletes, male and female athletes showed some significant differences. According to the data, male athletes were larger than others in $47 \%$ of their photos, while women were larger than others in only $27 \%$ of their photos. Besides, women were the same size as other people in $58 \%$ of their non-solo photos, while men were the same size in only $30 \%$ of their non-solo photos in this item.

There were also significant differences in the focus of the photos between the male and female swimmers. First of all, it can be seen from the data that female athletes were more likely to take selfies than male athletes, as $31 \%$ of the photos of female athletes were selfies, while only $13 \%$ of the photos of male athletes were selfies. Male athletes, however, were more concerned about whether they were the focus of their photos. According to the data, only $76 \%$ of female 
athletes' photos were focused on themselves, compared with $90 \%$ of male athletes.

For clothing, male athletes had more revealing/swimsuit photos than female athletes. Among them, male athletes' revealing/swimsuit photos accounted for $30 \%$ of the total number of male athletes' photos, of which $11 \%$ were non-swimsuit revealing photos. However, revealing/swimsuit photos of women made up only $9 \%$ of all photos of female athletes, and all of them were swimsuit photos.

In terms of breasts/buttocks, the researchers found that neither male nor female swimmers had significant sexual gestures. Only $7 \%$ of male swimmers highlighted their breasts or buttocks, with $6 \%$ showing chest/abs and $1 \%$ showing buttocks. None of the female swimmers highlighted their breasts or buttocks.

There was also differences in self-touch between men and women, with women touching themselves more often than men (22\% and $13 \%$, respectively). However, only one of the three women in the research had noticeable feminine touches in her photos. Interestingly, some male athletes have also posted photos of themselves holding their chin or touching their thighs, moves that are often considered feminine.

Q2 asked does Goffman's theory of gender display applies to the presentation of Chinese swimmers on social media. To answer this question, the researchers divided the data into five categories based on Goffman's gender display, namely: relative size, feminine touch, function rating, ritualization of subordination, licensed withdrawal.

Relative size: According to the data, $47 \%$ of the male athletes were larger than the others in their photos, while only $27 \%$ of the women were larger than the others. However, in $23 \%$ of the group photos, the male athletes were smaller than the others, while the figure for women was only $15 \%$. Besides, female athletes were the focus of $76 \%$ of their photos, compared with $90 \%$ of male athletes. In general, the relative size of the observed male athletes was greater than that of the female athletes when they chose photos of themselves in groups.

Feminine touch: As mentioned above, the differences between men and women in terms of 'touch' is apparent, the frequency of women showed more than men, they were $22 \%$ and $13 \%$ respectively. Nevertheless, the touches of female athletes were also more feminine; for example, they usually touch their faces, hold their chins, and put their hands between legs.

Function rating: Because male and female swimmers rarely work together in the same setting, there was no way to compare the function rating between them. Therefore the researchers chose to explore the functional identities that athletes prefer to present to the audience from the perspective of their photo content. According to the data, there was little difference between the male and female athletes in the item of "about work and sport", accounting for $38 \%$ and $39 \%$, respectively, with women slightly higher than men. Besides, in the item of "about business activities," men accounted for $1 \%$ and women $2 \%$, with women slightly more than men. However, female athletes were more enthusiastic about sharing their personal lives, with $59 \%$ of females' photos and $53 \%$ of males' photos in the "about their personal lives" category.

Ritualization of subordination: There was also little difference between men and women, with women showing head angles, body angles, and bashful knee bend on just $6 \%$ of their photos, compared with $4 \%$ for men. However, some of the movements that male athletes exhibited were related to training needs and pranks.

Licensed withdrawal: In this part, the differences between men and women were not visible, and in most of the photos, the athletes were emotionally positive. Photos of female athletes with the trait of licensed withdrawal accounted for $11 \%$, while photos of male athletes with this trait accounted for $8 \%$.

\section{DISCUSSION}

Previous studies have found gender differences in online self-presentation behaviors among athletes. This research attempted to expand the literature on gender differences in the performance of swimmers from the Chinese national swimming team in the direction of visual self-presentation.

\section{A. Gender differences of online self-presentation}

Q1 focused on the gender differences in the online visual self-presentation of Chinese national swimming team athletes. The researchers found some gender differences consistent with previous studies of athletes from countries outside China.

One of the most interesting of these gender differences is about selfies. According to Dhir et al. (2016), women are more enthusiastic about taking selfies and sharing photos than men. This claim was also confirmed in this research. That is, women share more selfies than men on the Chinese national swimming team. This situation may be due to the cartoon stickers in beauty camera and the beautification effect designed more specifically for the female face are more relevant to the interest of women. Moreover, Shreffler, Hancock and Schmidt (2016) believe that team athletes were more willing to take selfies and play the role of "the girl next door", while individual athletes were more inclined to show their athletic ability. However, this research produced different results. As 
an individual sport, both male and female swimmers were more inclined to share their personal lives than their athletic abilities.

Another notable gender differences are the clothing of athletes and the way their breasts/buttocks were highlighted. According to Clavio and Eagleman (2011), photos of female athletes portrayed by many sports blogs are associated with sexual injunctions, which can affect the social perception of women and the development of body image of young female athletes. However, the results of the research suggested that female athletes were less likely to associate themselves with sex when they can present themselves without the media. Male athletes, on the other hand, are more or less topless, highlighting their chest or abdominal muscles as a natural expression of masculinity. This phenomenon may be due to the vanity of male athletes, as most of them have the physical qualities that they are proud of and have worked on for years (Smith and Sanderson, 2015).

\section{B. Applicability of gender display in online impression management}

Q2 focuses on the applicability of Goffman's gender display in the online visual representation of Chinese national swimming team athletes. This research found that the framework of gender display is not only applicable to the advertising field but also athletes' selfpresenting behaviors on the Internet. Among them, the most worthy of discussion are "relative size", "feminine touch" and "function rating". According to Goffman (1976) relative size can be defined as a way in which social weights such as power, authority, rank, position, prestige are expressed in social situations through size (especially the size of height). He claims that in advertisements, the highest, foremost or most noticeable figures are usually men, who represent power, while women are always portrayed as less important. In addition, Smith and Cooley (2012) also state that power is usually displayed by the distance of people in photos, which leads to that men are usually closer or larger than women in photos. While this research did not focus on advertising, but the results consistent with Goffman's "relative size" theory. In other words, when male and female swimmers presented themselves, male swimmers were more likely than female swimmers to show photos that were centered on them or made them appear larger than others. In contrast, women were more likely to show themselves the same size as the others in group photos. However, this phenomenon may not related to social status, as most of the samples were photographed with members of the same sex rather than the opposite sex.

Feminine touch was another noteworthy point in this research. Consistent with the research of Smith and Sanderson (2015), female athletes of Chinese national swimming teams had more touching behaviors than male athletes. Further, these behaviors were often considered as femininity, such as touching faces, holding the chins and hands between legs. These behaviors may be related to" feminine "education and imitating other women's photo poses. However, it is worth noting that some male athletes also performed feminine touch associated movements, such as "holding the chin", "touching hair", which contradicted previous studies in which men showed resistance to touching themselves.

Finally, function rating was also an interesting point in this research, which presented inconsistent results with Goffman's result in advertising research. According to Goffman (1976), when men and women collaborate on a professional task, men play the leading executive role, while women play a lower role. However, this research sought to investigate whether there were gender-specific function ratings in the selfpresentation of men and women when they were not collaborating. Ultimately, the results showed that both male and female athletes were less likely to associate their images with "professional" or "executive" status. Instead, they were more eager to share their personal lives, such as playing, eating, and family life, which makes the phenomenon of functional rating rarely presented in their online self-presentation.

\section{CONCLUSION}

This research found that there were gender differences in the visual self-presentation of the Chinese national swimming team members. For example, male athletes were more likely than female athletes to show off their bodies, such as topless, highlighting chest and abs, while female athletes tended to be more conservative. Additionally, female athletes tend to display selfies more often than male athletes. Apart from that, this research also found that some of the concepts in Goffman's gender display applied to the online self-presentation of the Chinese national swimming team's athletes. For example, female athletes had more feminine touches than male athletes, and their relative sizes were also smaller than that of male athletes. However, it is worth noting that functional ratings did not apply to self-presentation on Chinese national swimming team members' social media, because both male and female athletes were not too keen to share their professional lives.

Furthermore, this research also had limitations. The first limitation was the number of samples. Because there were not many active swimmers in the Chinese national swimming team who not only used Weibo but also had a large number of fans, there were some difficulties in the selection of samples. In the end, the researchers could only select three male and three female athletes' Weibo photos for analysis, which made 
the number of samples not rich enough to produce enough data and more objective results. Likewise, this research only focused on the visual presentation of the athletes and did not pay attention to the captains of their photos. However, when people post pictures, they usually more or less accompany some text messages to illustrate the pictures. In this situation, if analyzing both text and photos, the researchers were able to gain a better understanding of the swimmers' photos. Therefore, future research of Chinese athletes' selfpresentation on social media should pay more attention to the research methods of both text analysis and content analysis, as well as the connection between online identity and offline identity of these athletes.

\section{References}

[1] Alan., Bryman (2011). Business research methods. Bell, Emma, 1968- (3rd ed.). Cambridge: Oxford University Press

[2] Barton, E. (2004). Discourse methods and critical practice in professional communication: The front-stage and back-stage discourse of prognosis in medicine. Journal of Business and Technical Communication, 18(1), 67-111.

[3] Clavio, G., \& Eagleman, A. N. (2011). Gender and sexually suggestive images in sports blogs. Journal of Sport Management, 25(4), 295-304.

[4] Dhir, A., Pallesen, S., Torsheim, T., \& Andreassen, C. S. (2016). Do age and gender differences exist in selfie-related behaviours?. Computers in Human Behavior, 63, 549-555.

[5] Emmons, B., \& Mocarski, R. (2014). She poses, he performs: A visual content analysis of male and female professional athlete Facebook profile photos. Visual Communication Quarterly, 21(3), 125-137.

[6] Geurin-Eagleman, A. N., \& Burch, L. M. (2016). Communicating via photographs: A gendered analysis of Olympic athletes' visual self-presentation on Instagram. Sport management review, 19(2), 133-145.

[7] Goffman, E. (1976). Gender display. In Gender advertisements (pp. 1-9). Palgrave, London.

[8] Hogan, B. (2010). The presentation of self in the age of social media: Distinguishing performances and exhibitions online. Bulletin of Science, Technology \& Society, 30(6), 377-386.

[9] Kassing, J. W., \& Sanderson, J. (2010). Fan-athlete interaction and Twitter tweeting through the Giro: A case study. International Journal of Sport Communication, 3(1), 113-128.

[10] Lebel, K., \& Danylchuk, K. (2014). An Audience Interpretation of Professional Athlete Self-Presentation on Twitter. Journal of Applied Sport Management, 6(2).

[11] Marshall, P. D. (2010). The promotion and presentation of the self: Celebrity as a marker of presentational media. Celebrity Studies, 1(1), 35-48.

[12] Paul, J., \& Sheets, E. (2012). Adapting Erving Goffman's 'Gender Advertisements' to Interpret Popular Sport Depictions of American Indians. International Journal of Humanities and Social Science, 2(24), 71-83.

[13] Pegoraro, A. (2010). Look who's talking-Athletes on Twitter: A case study. International journal of sport communication, 3(4), 501-514.

[14] Serpa, S., \& Ferreira, C. M. (2018). Goffman's backstage revisited: Conceptual relevance in contemporary social interactions. International Journal of Social Science Studies, 6(10), 74-80
[15] Shreffler, M. B., Hancock, M. G., \& Schmidt, S. H. (2016). Self-presentation of female athletes: A content analysis of athlete avatars. International Journal of Sport Communication, 9(4), 460-475.

[16] Smith, L. R., \& Cooley, S. C. (2012). International faces: An analysis of self-inflicted face-ism in online profile pictures. Journal of Intercultural Communication Research, 41(3), 279 296.

[17] Smith, L. R., \& Sanderson, J. (2015). I'm going to Instagram it! An analysis of athlete self-presentation on Instagram. Journal of Broadcasting \& Electronic Media, 59(2), 342-358

[18] Wallace, L., Wilson, J., \& Miloch, K. (2011). Sporting Facebook: A content analysis of NCAA organizational sport pages and Big 12 conference athletic department pages. International Journal of Sport Communication, 4(4), 422-444.

[19] Wallis, C. (2011). Performing gender: A content analysis of gender display in music videos. Sex Roles, 64(3-4), 160-172.

[20] Wang, Q., 2018. Goffman On Gender Advertisements: Based on the Perspectives of Ritual and Frame Analysis. Journal of Chinese Women's Studies, 148(4), pp.64-75.

[21] White, M. and Marsh, E., (2006). Content Analysis: A Flexible Methodology. Library Trends, 55(1), pp.22-45.

[22] Zhao, X., Salehi, N., Naranjit, S., Alwaalan, S., Voida, S., \& Cosley, D. (2013, April). The many faces of Facebook: Experiencing social media as performance, exhibition, and personal archive. In Proceedings of the SIGCHI conference on human factors in computing systems (pp. 1-10) 